\title{
Understanding the social and community support networks of American Indian women cancer survivors
}

\author{
Yeon-Shim Lee ${ }^{a}$, Catherine E. Burnette ${ }^{b}$, Jessica Liddell ${ }^{c}$, and Soonhee Roh ${ }^{c}$ \\ aSchool of Social Work, San Francisco State University, San Francisco, CA, USA \\ bSchool of Social Work, Tulane University, New Orleans, LA, USA \\ 'Department of Social Work, University of South Dakota, Sioux Falls, SD, USA
}

\begin{abstract}
Cancer is the leading cause of death among American Indian and Alaska Native (AI/AN) women. Although cancer disparities among AI women are alarming, there is littlle research focused on the topic of social support and cancer treatment and outcomes. A community advisory board was used to develop and administer the project, and a qualitative descriptive study methodology was used. This research was conducted in partnership with two community-based hospitals in the Northern Plains.

The sample included $43 \mathrm{AI}$ female cancer survivors who were interviewed with a semi-structured interview guide. The data were analyzed using content analysis. Emergent themes revealed that AI cancer survivors' non-familial support systems included friends $(n=12)$, support groups $(n=6)$, churches $(n=10)$, co-workers $(n=5)$, communities $(n=4)$, support from health practitioners $(n=$ 3 ), and additional forms of support. Results indicate that survivors' networks are diverse and support broad prevention programs that reach out to churches, community groups, and online forums. These sources of supports can be enhanced through sustainable community-based infrastructures.
\end{abstract}

\section{Keywords}

American Indian/Alaska,Native; Native American; Indigenous; cancer; women; social support; qualitative research

Cancer is the leading cause of death among American Indian and Alaska Native (AI/AN) women (Espey et al., 2014). AI/AN women experience it at a rate 1.6 times that of Caucasian women (Espey et al., 2014). Although historically the data on AI/AN cancer has been scarce, the most reliable data has included death records and cancer incidence records from state cancer registries, which have been linked with Indian Health Service registration data to identify AI/AN people correctly (Centers for Disease Control [CDC], 2016). Overall, these data indicate that cancer death rates for Caucasian people declined more quickly than

CONTACT Soonhee Roh Soonhee.Roh@usd.edu Associate Professor, Department of Social Work, University of South Dakota, 365 Health Science Center, 1400 West 22nd street, Sioux Falls, SD 57105. 
for AI/AN people, and between the years of 2001 and 2009, death rates actually increased for $\mathrm{AI} / \mathrm{AN}$ men and women (CDC, 2016).

The rates of cancer incidence, along with death rates, often vary by cancer type, region, and sex. For example, although lung cancer has decreased among AI/AN men since 1997, for AI/AN women it has continued to increase (Plescia, Henley, Pate, Underwood, \& Rhodes, 2014). For ovarian and uterine cancer, AI/AN women and Caucasians have similar cancer death rates, yet these rates vary substantially by geographic region (Singh, Ryerson, $\mathrm{Wu}, \&$ Kaur, 2014). Although the rates of breast cancer deaths tend to be lower for AI/AN women overall, it is concerning that they have not seen the same decline in death rates that Caucasian women have experienced (White, Richardson, Li, Ekwueme, \& Kaur, 2014). For colorectal cancer, incidence rates are higher overall for AI/ANs, and AI/AN women experience higher death and incidence rates than both their male counterparts and Caucasian women (Perdue, Haverkamp, Perkins, Daley, \& Provost, 2014). Finally, kidney cancer incidence and death rates for AI/ANs are nearly twice that of Caucasians, with AI/AN women experiencing significantly higher rates than both AI/AN men and Caucasian women (Li et al., 2014). Although cancer disparities among AI women (to whom the scope of this article is limited) are alarming, there is a dearth of research focused on the topic, particularly on the social and community support networks among these women (Bauer, Englert, Michalek, Canfield, \& Mahoney, 2005).

\section{Social support}

Social support is an important factor influencing the quality of life among cancer survivors (Luszczynska, Pawlowska, Cieslak, Knoll, \& Scholz, 2013). Social support has been found to be particularly protective against the progression of breast cancer among women in the general U.S. population (Nausheen, Gidron, Peveler, \& Moss-Morris, 2009). Although social support has been found to be associated with positive AI coping with cancer (Zucca, Boyes, Lecathelinais, \& Girgis, 2010), only one article was found that explicitly focused on social support among AI women with cancer (Bauer et al., 2005). AI/ANs belong to 567 federally recognized tribes (Bureau of Indian Affairs, 2017), along with state recognized tribes and tribes outside either jurisdiction, with a trust responsibility that requires the U.S. Federal Government to provide for their healthcare (U. S. Commission on Civil Rights, 2004). Given the significant disparities at present, the goals of this trust responsibility have not been met (U. S. Commission on Civil Rights, 2004).

Because cancer rates and associated factors tend to differ by geographic region, gender, and age, ethnic identity and culture may also play an important role in impacting the social support experiences of AI women's cancer survivors. AI women utilize support from their social networks to cope with a range of health problems, including cancer (Canales, 2004; Guadagnolo et al., 2009). Social supports may be especially important for AI women cancer survivors because they are better suited to address some of the social and psychological effects of cancer that extend beyond the physical impact of cancer (Sammarco \& Konecny, 2008; Sapp et al., 2003; Wyatt \& Friedman, 1996). Cancer survivors living in rural areas may be particularly vulnerable because they are at increased risk for social isolation, because of the long distances frequently required to travel to access services, and the limited ability 
for them to receive continual monitoring of their physical and mental wellbeing (Doorenbos et al., 2010; Wilson, Andersen, \& Meischke, 2000). Previous research has also suggested that rural cancer survivors may especially need additional emotional support following cancer diagnosis because of the increased infrastructure barriers they face (Wilson et al., 2000).

Support in AI communities is often characterized by a mixture of both formal and informal resources and tribally based assistance, and the forms this takes can vary substantially by tribe (Beals et al., 2014; Buchwald, Beals \& Manson, 2000). Because of the long history of inadequate health and social services, informal forms of support, such as that provided by the community or friends, may be especially salient for AI cancer survivors (Canales, 2004; Canales et al., 2011; Garrett, Baldridge, Benson, Crowder, \& Aldrich, 2015). Furthermore, some patients may avoid, or have ambivalent feelings about receiving support from formal institutions, such as hospitals or social service agencies, because of this history of oppression, making an analysis of the role of informal social supports especially relevant (Broome \& Broome, 2007; Burnette, 2015; Burnette \& Figley, 2017; Canales, 2004; Canales et al., 2011; Garrett et al., 2015).

Bauer et al.'s (2005) article examined the social network topology of 40 AI cancer patients with 41 non-AI controls. Despite no differences being identified across the topologies of AIs and non-AIs, expressive social supports (e.g., companionship, emotional support, and advice) were reported as the most important by all (Bauer et al., 2005). Instrumental support (e.g., financial, favors, household maintenance) was not ranked as important (Bauer et al., 2005). Bauer et al. (2005) reported that these forms of support came from distinct sources, with companionship most often coming from friends, prayers coming from church support, and instrumental support coming from family (Bauer et al., 2005). Given the striking absence of research on AI women cancer survivor's social support, the purpose of this research was to explore their non-familial social and community support networks.

\section{Methods}

\section{Research design}

This research was informed by the creation of a community advisory board (CAB), which consisted of AI leaders in the community, healthcare practitioners from the AI community, and social workers from community social service agencies. The CAB's mutually agreed upon primary tasks were to: (1) identify project-related community resources and topics of concern; (2) provide guidance on how to recruit participants, along with the presenting of results; and (3) promote community engagement and support for this research. A qualitative descriptive study design explored the non-familial social support experiences of AI women cancer survivors. The overarching research questions were: (1) "Who do American Indian women cancer survivors go to for social and community support?" and (2) "What types of support do they receive?"

Qualitative description is a naturalistic inquiry where themes emerge inductively from the data with a goal of a rich account of experience that is then presented in easily accessible language (Sullivan-Bolyai, Bova, \& Harper, 2005). This can be germane to working with 
ethnic minority populations and for understanding cultural distinctions, because it describes a phenomenon with participants' own words rather than through the more theoretical explanations of researchers (Sullivan-Bolyai et al., 2005). Sandelowski (1996) and SullivanBolyai et al. (2005) have stated that this method enhances the internal validity of studies because it seeks to answer questions in participants' own words and decreases competing explanations.

\section{Setting and sample}

This project was done in partnership with two distinct community-based hospitals in the Northern Plains: (a) the John T. Vucurevich Cancer Care Institute, Rapid City Regional Hospital in Rapid City, Western South Dakota; and (b) the Avera Medical Group Gynecologic Oncology in Sioux Falls, Eastern South Dakota. These sites were picked because they are the primary community/regional hospitals AI women in the Eastern and Western parts of South Dakota utilize.

The sample includes $43 \mathrm{AI}$ female cancer survivors ( $n=14$ cervical cancer, $n=15$ colon cancer, and $n=14$ breast cancer, and other types of cancer survivors). The topic of social support was explored across cancer types to assess the underlying themes of cancer survivors' social support systems, rather than looking for differences based on cancer type (although the potential for differences across cancer type was assessed in the data analysis process). Purposeful sampling was used to identify which individuals would be best able to answer questions about female AI experiences with cancer. New participants stopped being recruited after the data reached saturation (when no additional meaningful findings were attained in interviews) (Sandelowki, 1995). Criteria for inclusion in the study entailed: (a) a history of cancer within the past 10 years; (b) completion of cancer treatment and having no recurrence of cancer at time of the interview; (c) identifying as female; (d) being over the age of 18; and (e) residing in South Dakota.

Table 1 presents a summary of selected demographic characteristics. Among participants, ages ranged from 32 to 77 , with a mean of 56.33 years ( $S D=12.07$ ). For education, 97.7\% $(n=42)$ of participants had at least a high school degree/GED. Approximately $49 \%(n=21)$ of participants' household monthly income was less than $\$ 1,499$. While $32.5 \%(n=14)$ of the sample self-reported their health as poor or fair, $67.5 \%$ reported good or excellent health $(n=29)$. The cancer-type of participants included: breast $(n=14,32.6 \%)$; cervical $(n=14$, $32.6 \%)$; colon ( $n=5,11.6 \%)$; lung ( $n=2,4.7 \%)$; Non-Hodgkin Lymphoma $(n=2,4.7 \%)$; and others $(n=6,13.9 \%)$. The majority of respondents $(n=39,90.7 \%)$ described engaging in religious practices, and 93\% $(n=40)$ of participants had some form of medical insurance. Finally, the amount of time participants had cancer was, on average, 2.42 years $(S D=2.19)$.

\section{Data collection}

Prior to the recruitment of participants, approval from the Institutional Review Board was provided from four institutions: (a) Avera McKennan Hospital, (b) University of South Dakota, (c) Sanford Research Center, and (d) Rapid City Regional Health. Before being interviewed, participants received information about the study and informed consent and 
signed a consent form. The principal investigator (PI) of this project and two trained researchers who had extensive experience with AI samples conducted the interviews.

Participant recruitment included mailing fliers to cancer survivors at the focal hospitals, posting fliers, public radio and newspaper announcements, along with word-of-mouth recruitment at churches and/or community agencies. Among the 46 who responded, the three respondents with over 10 years of cancer experience were excluded, resulting in the final sample of 43 participants. Interviews took place at the locations preferred by participants (i.e., participants' personal residence, a private room at the hospital, a secluded conference room at community church, and the author's office) between June 2014 and February 2015.

The semi-structured interview script was created in collaboration through a series of meetings with the $\mathrm{CAB}$. Qualitative questions were developed through combining topics related to cancer research together with community priorities and needs expressed by the $\mathrm{CAB}$. The $\mathrm{CAB}$ assessed the guide for cultural relevance and appropriateness and ensured the relevance and readability of questions to AI women cancer survivors. Examples of interview questions included, "Do you have a support system outside of those in your family? What forms of support have you received from them?" The interviews, which were audio-recorded, ranged from 30 minutes to 2 hours in length, and participants were paid $\$ 50$ cash for their participation. An additional gift card was provided to cover any travel or expenses related to participation. Three master of social work students transcribed the interviews, which were entered into NVivo (2015) data software for analysis.

\section{Data analysis}

Data analysis followed qualitative content analysis, the analysis suggested for qualitative descriptive methodologies (Milne \& Oberele, 2005; Sandelowski, 2000; Sullivan-Bolyai et al., 2005), and which allows codes to come from the data itself (Milne \& Oberele, 2005).

First, immersion was achieved by author(s) reading and listening to interview transcriptions several times to gain a sense of the whole. Second, exact words were highlighted and notes were made to identify important concepts. Third, 430 initial meaning units were derived (Graneheim \& Lundman, 2004). Fourth, initial codes were organized into overarching categories with sub-clusters under each. Co-authors checked and validated these categories and sub-clusters and examined whether any recurrent patterns of variation were present across cancer types. After no such differences were found, categories were organized into meaningful groupings, and a definition was made for each grouping (Patton, 2002). Sixth, emergent clusters with their related quotes were presented to participants for member checking (i.e., ensuring interviews and interpretations of interview findings were correct, according to participants' perspectives). All participants were invited to participate in member checking, with over half $(n=23,53.5 \%)$ participating in this process. Research team members reached out on three occasions for member checks, although close to half of participants $(n=21,46.5 \%)$ had phones that were disconnected and could not be reached. 


\section{Strategies for rigor}

Using Milne and Oberele's (2005) guidelines to enhance rigor in qualitative descriptive studies, (a) authenticity (i.e., remaining true to the aim of the research); (b) credibility (i.e., the trustworthiness of findings); and (c) criticality (i.e., strategic decision-making throughout the research process) were ensured in the following ways: (a) using a semi-structured interview guide to encourage participants to speak freely; (b) ensuring that participants' thoughts and voices were prioritized by inquiring and clarifying participants' meanings; (c) ensuring that participants' intended meanings were precisely represented by facilitating member checks; and (d) ensuring that coding was inductively derived from the data through the choice of conventional content analysis, an inductive analysis method. In addition to the strategies already listed, authenticity was promoted by engaging in peer review and reflecting on potential bias to ensure study integrity (Milne \& Oberele, 2005).

\section{Results}

AI survivors' support systems included friends, church, cancer survivor and related support groups, community and neighborhood support, and support from health practitioners. It should be noted that although $64 \%(n=27)$ of participants described some form of support system(s) outside of the family, 69\% $(n=29)$ of participants also described the need for additional social support. The forms of social support outside family included friends ( $n=$ 12), which encompassed friends who were both cancer survivors and those who had not experienced cancer, and from in-person and online support groups $(n=6)$; support from church $(\mathrm{n}=10)$; co-worker support $(n=5)$; community and neighborhood support $(n=4)$; and support from health practitioners $(n=3)$. In the following themes, participants were given anonymous numbers to demonstrate that quotes arose across a variety of women while also maintaining participant anonymity.

\section{Friend support}

AI cancer survivors found friends through personal connections, support groups, and online social media. These friends provided both emotional and instrumental support to AI cancer survivors. Some women reported this support from friends entailing friends checking in on them and praying for them. When asked about her support system, Participant 21 mentioned, "I had a lot of friends that would call and say they were praying for you. You know, that was really big." Participant 20 talked about her friend and survivor support system, "I have good friends that check on me. Some are on Facebook and some are just private friends that check on me." She added, "There is a support group here." Participant 27 went to a cancer survivor support group, because she said, "I felt, you know, welcomed." Participant 24 stated, "I have a few friends that are cancer survivors. And then I'm on an online support group."

Women found support through both in-person friends, as well as connections on social media. Participant 18 also stated:

I had friends that were very supportive, and I also had the support of other females who had breast cancer who I could talk to, and I also went online ... where they had chat rooms where they could talk with other survivors. 
Some women received additional emotional support through non-cancer-related support groups like Alcoholics Anonymous (AA). Participant 13 stated, "Yes, I have close friends. People that are in the church, and people that are in AA," who offered, "listening, a shoulder to lean on, prayers." Participant 4 also mentioned, "I have the AA group and friends that I have. You know I have several good friends that I can lean on times of need." Women received support from friends who came from a diverse range of sources, including friends who provided emotional and instrumental support specifically related to their cancer, and friends who provided general support. Women also received support from both friends that were both physically present and from friends on online sources.

\section{Church support}

Church support was another source of support for AI women with cancer. Women conceptualized this support as both coming from individuals at the church and coming from the church community as a whole. Similar to the form of support offered by friends, church support took the form of both emotional and instrumental support. Participant 28 described:

I have a lot of Christian woman who are friends. ... and they would just call me and see how I was doing and they would stop by if they were in the area and they would just come and let me know that they were thinking about me and they were praying for me.

Providing an example of the simultaneous emotional and instrumental support offered through the church, Participant 28 appreciated, "Their encouragement and their visits and they would send gifts."

Church support also appeared to be unique because of its regularity and dependability for participants. Participant 22 described the importance of her consistent church support, "I call every once in a while, for prayer. We see each other about once a week." In describing the type of support Participant 22 received from her church network, she added: "I had an offer to give me a ride if I needed it, from one lady, she said she'd give me a ride to the doctor if I needed it." Participant 17 described her church community, stating:

Those people are really nice. They brought us cooked meals for a week and they checked on us, called, see how I was feeling. The pastor prayed for us and everything. You know, they were a good support there too.

Finally, participant 35 described, "I'm a Catholic. And it's really supportive. We all take care of each other. We're all there for each other when something happens." Religious support was also not limited to Christian practices and churches, with participants also noting support from other spiritual figures. Participant 34 noted about her spiritual leader: "She really encourages the sweet grass and the smudging. She really does encourage that. She really is a wonderful woman. We're really blessed to have her." Church support took a variety of forms for participants and was especially important not only because of the practical and emotional resources it provided, but also because of its connection to participants own faith and beliefs. 


\section{Co-worker support}

Several women mentioned the importance of co-worker support. As with other forms of support, participants described their co-workers as offering a mixture of types of support. As Participant 16 described:

They were beautiful at my workplace. ...My boss said, she owned the place, she said if I felt sleepy I could go sleep on my car or lay on the couch or go home, and they would pick up the slack from my treatments.

Participant 5 also described co-worker support, "Like some of them would come over with me and visit with me and say, 'Oh _ _, you're back!' ... and they come in, and I give them coffee or tea, and we visit." Co-worker support was important for providing individuals with emotional and instrumental support in their professional lives, distinguishing it from the support they received from other sources.

\section{Community and neighborhood support}

Community and neighborhood resources was an additional source of social support for participants. Regarding the AI community, close to half $(43 \%, n=18)$ indicated that they did not feel support, whereas about $21 \%(n=9)$ indicated they did feel support, from both the AI community and the general community (total $43 \%, n=18$ ). For some participants, the importance of this source of support is that it provides a distraction from cancer itself. Participant 12 spoke about her neighborhood friends' support being comprised of companionship and fun, describing: "Well, they come over and visit and talk. We talk about different things, a long time ago, things that happened a long time ago, and we laugh, you know ... They bring a movie over, and we watch movies." Alternatively, some participants described this support as being important because of the connection they felt over sharing a personal experience about cancer. This included the importance of connecting with individuals who themselves had not had cancer but could relate and provide empathy. Participant 8 spoke about a neighborhood friend who was supportive to her, stating, "I have a neighbor that was really concerned, and she talked to me, and she had a daughter that passed away with breast cancer. ... She'd have like little walks, or little healing services." Not only were neighbors important, the support from other AI community and tribal members was significant. Participant 20 described this:

I think that, um, the Indian, Native community, we always feel at the bottom of some list. We're always the least educated, we're always the poorest, we're always the unhealthiest. So I think that the Native community kind of can band together like that and support each other. I feel that.

However, some women identified the need for further support in this area and reported being frequently frustrated with the perceived lack of local sources of support while in care. Participant 34 reported:

None. We don't have a support system here. I wish there was. Like with American Indian women who are going through this because there is not a lot of support out here. I mean like I said since I've had it I can't talk to anybody around here about it because there isn't no support system out here. Like I said, if you need to talk to 
somebody about it, they'll refer you to Rapid City or they'll refer you to somewhere else to get counseled or to go talk to somebody.

For some participants, support and need for support from their community was especially important because of their shared history of oppression. Support from the neighborhood and community was reported as being important for many participants and as before, providing both emotional and instrumental support for participants.

\section{Health practitioners}

Finally, some women expressed the importance of the support provided by caring health practitioners. Participant 35 stated, "My nurse midwife was great. She is very caring and then she's very understanding and she was very supportive." Likewise, Participant 34 specified:

Who I really talked to was my doctor, [name of Dr.], before he passed ... I'd call to his clinic and the nurses would relay a message to him and if he's not busy he'll talk to me. If he's busy, he'll leave a message and call me back. So he was my support system, I mean through that clinic.

This support appeared to be instrumental in that the health practitioners provided medical care for the participants, but also is important because of the emotional connection facilitated by these caring health providers. Participants highlighted the importance of thoughtful and caring communication on the part of healthcare practitioners. However, few participants reported receiving this support, highlighting the important role of non-formal supports for women.

\section{Discussion}

Several interesting themes emerged across participants. Importantly, these findings were present across all types of cancer survivors (e.g., breast and cervical.), indicating that cancer type was not a salient difference related to types of social support. To begin, friendships were the most common form of non-family social support, followed by church support, community and neighborhood support, and support from health practitioners. Few women reported receiving substantial health practitioner support, emphasizing the importance of non-formal support systems for AI women with cancer. Moreover, women gained access to friendships, not only through personal and community connections, but also through online forums. This may be particularly important for women residing in rural areas to find connection where access to in-person support services may be limited.

Furthermore, despite women receiving support from a variety of sources, the forms of support were remarkably consistent. "Checking on" women and "praying for" women were mentioned for both friendships and church support as important. This differs from Bauer et al.'s (2005) finding that different types of support provide differing forms of social support (i.e., instrumental or expressive). Offering instrumental support through rides to a doctor's appointment or providing meals made a difference for women. Instrumental support was provided by friends and church support, whereas for Bauer et al.'s (2005) study, this instrumental support was primarily offered by family. Offering emotional support by letting 
women share their struggles with cancer was important, as well as offering companionship and fun through conversations, games, and get-togethers. Many of the support systems reported were regularly scheduled, such as support groups and church, indicating that the regularity of the meetings of support may be important. Finally, women also found support through non-cancer-related support groups such as AA. This was a surprising finding and suggests that conventional conceptualizations of cancer support groups may need to be broadened, and that this support may take multiple forms.

\section{Future research and limitations}

Future research examining family support is needed. This qualitative study is not generalizable beyond its context. The focus of this inquiry was to identify who and what types of support AI women cancer survivors reported. Although distinctions across participants with varying types of cancer were not found, future studies should build upon this work with different groups and larger samples, and supplement it with quantitative studies. There is much heterogeneity across the 567 tribes and regions and across both urban and rural areas, and these differences need to be examined with regard to specific contexts (Bureau of Indian Affairs, 2017).

\section{Implications for social work practice}

Several important implications can be drawn from these results. First, although the sources of support may differ, the forms of support provided were consistent. This can be an important point for health promotion. For example, community education programs and educational pamphlets can be created for distribution at churches or community centers, providing information on how people can further support cancer survivors. Specific support strategies were mentioned by survivors, such as "checking on" the survivor, "offering prayer" to those who practice a faith tradition, "listening," "offering to help with rides, meals and other daily needs," and "doing fun things" with survivors. These strategies can be infused into educational materials, which may be relevant across types of cancer, adapting the specific information to each cancer type accordingly. Women also reported finding support through non-cancer-related support groups, such as AA. This was a surprising finding and suggests that cancer screening, education, and support programs may need to be expanded to think beyond conventional arenas.

Additionally, because research shows that being isolated from one's identity is understood to contribute to poor health, and Indigenous identity is often highly social, programs that facilitate building upon these social support networks may be more likely to be beneficial for, desired, and well-received, by AI cancer survivors (King, Smith, \& Gracey, 2009). Several participants reported the importance of both their Native identity and their religious affiliation. Some possibilities for how social support programs could be expanded for AI women with cancer include the example of cancer programs that use a "Native sister" model in which an AI women with cancer is paired with another AI "sister" who provides emotional support throughout the cancer screening and treatment (Burhansstipanov, 1998). This may be especially important because many participants reported not feeling support and connected to their community. 
These results indicate that a diverse array of people make up the cancer survivor's support network, indicating the need for broad prevention programs that reach out to churches, a variety of community groups, and online forums. Online supports may be an important way to address the growing need identified for survivors in rural areas and may provide ways for survivors in diverse geographic contexts to connect. These results suggest that social support can take multiple forms and can come from both cancer-related and more general social support systems. They also indicate that women frequently rely on non-formal support systems. Perhaps additional formal support systems should be developed to further supplement these non-formal systems. Survivors appear to benefit from both emotional and instrumental support from these sources. The roles that these supports play can be enhanced for sustainable community-based infrastructures that may be protective for cancer survivors.

\section{Acknowledgments}

This research was supported by funding from the National Institute on Minority Health and Health Disparities (U54MD008164 by Elliott) from the National Institutes of Health to Soonhee Roh, PhD. This work was also supported, in part, by Award K12HD043451 from the Eunice Kennedy Shriver National Institute of Child Health \& Human Development of the National Institutes of Health (Krousel-Wood-PI; Catherine Burnette-Building Interdisciplinary Research Careers in Women's Health (BIRCWH) Scholar).

Funding

This work was supported by the National Institute on Minority Health and Health Disparities [U54MD008164]; Eunice Kennedy Shriver National Institute of Child Health \& Human Development of the National Institutes of Health [K12HD043451].

\section{References}

Bauer JE, Englert JJ, Michalek AM, Canfield P, \& Mahoney MC (2005). American Indian cancer survivors: Exploring social network topology and perceived social supports. Journal of Cancer Education, 20(1), 23-27. doi:10.1207/s15430154jce2001s_06

Beals J, Novins DK, Whitesell NR, Spicer P, Mitchell CM, \& Manson SM (2014). Prevalence of mental disorders and utilization of mental health services in two American Indian reservation populations: Mental health disparities in a national context. American Journal of Psychiatry, 162(9), 1723-1732.

Broome B, \& Broome R (2007). Native Americans: Traditional healing. Urologic Nursing, 27(2), 161163, 173. [PubMed: 17494460]

Buchwald D, Beals J, \& Manson SM (2000). Use of traditional health practices among Native Americans in a primary care setting. Medical Care, 38(12), 1191-1199. [PubMed: 11186298]

Burnette CE (2015). Historical oppression and intimate partner violence experienced by Indigenous women in the United States: Understanding connections. Social Service Review, 89 (3), 531-563.

Burnette CE, \& Figley CR (2017). Historical oppression, resilience, and transcendence: Can a holistic framework help explain violence experienced by Indigenous people? Social Work, 62(1), 37-44. [PubMed: 28395035]

Bureau of Indian Affairs. (2017). What we do. Retrieved from https://www.bia.gov/index.htm

Burhansstipanov L (1998). Cancer mortality among Native Americans. Cancer, 83, 2247-2250. doi: 10.1002/(ISSN)1097-0142 [PubMed: 9840522]

Burhansstipanov L, \& Hollow W (2001). Native American cultural aspects of oncology nursing care. Seminars in Oncology Nursing, 17, 206-219. doi:10.1053/sonu.2001.25950 [PubMed: 11523487]

Canales M (2004). Taking care of self: Health care decision making of American Indian women. Health Care for Women International, 25, 411-435. doi:10.1080/07399330490438323 [PubMed: 15204811] 
Canales MK, Weiner D, Samos M, Wampler NS, Cunha A, \& Geer B (2011). Multi-generational perspectives on health, cancer, and biomedicine: Northeastern Native American perspectives shaped by mistrust. Journal of Health Care for the Poor and Underserved, 22, 894-911. doi: 10.1353/hpu.2011.0096 [PubMed: 21841286]

Centers for Disease Control and Prevention (CDC). (2016). Health disparities in cancer: Cancer among American Indians and Alaska Natives. Retrieved from https://www.cdc.gov/cancer/ healthdisparities/what_cdc_is_doing/aian.htm

Doorenbos AZ, Eaton LH, Haozous E, Towle C, Revels L, \& Buchwald D (2010). Satisfaction with telehealth for cancer support groups in rural American Indian and Alaska Native communities. Clinical Journal of Oncology Nursing, 14(6), 765-70. [PubMed: 21112853]

Espey DK, Jim MA, Cobb N, Bartholomew M, Becker T, Haverkamp D, \& Plescia M (2014). Leading causes of death and all-cause mortality in American Indians and Alaska Natives. American Journal of Public Health, 104, S303-311. doi:10.2105/AJPH.2013.301798 [PubMed: 24754554]

Garrett MD, Baldridge D, Benson W, Crowder J, \& Aldrich N (2015). Mental health disorders among an invisible minority: Depression and dementia among American Indian and Alaska Native elders. The Gerontologist, 55(2), 227-236. [PubMed: 26035598]

Graneheim UH, \& Lundman B (2004). Qualitative content analysis in nursing research: Concepts procedures and measures to achieve trustworthiness. Nursing Education Today, 24, 105-112. doi: 10.1016/j.nedt.2003.10.001

Guadagnolo BA, Cina K, Helbig P, Molloy K, Reiner M, Cook EF, \& Petereit DG (2009). Assessing cancer stage and screening disparities among Native American cancer patients. Public Health Reports, 124, 79-89. doi:10.1177/003335490912400111 [PubMed: 19413030]

King M, Smith A, \& Gracey M (2009). Indigenous health part 2: The underlying causes of the health gap. [Indigenous health part 2: The underlying causes of the health gap]. The Lancet, 374, 76-85. doi:10.1016/S0140-6736(09)60827-8

Li J, Weir HK, Jim MA, King SM, Wilson R, \& Master VA (2014). Kidney cancer incidence and mortality among American Indians and Alaska Natives in the United States, 1990-2009. Journal Information, 104, 396-403.

Luszczynska A, Pawlowska I, Cieslak R, Knoll N, \& Scholz U (2013). Social support and quality of life among lung cancer patients: A systematic review. Psycho-Oncology, 22, 2160-2168. [PubMed: 23097417]

Milne J, \& Oberele K (2005). Enhancing rigor in qualitative description: A case study. Journal of Wound Ostomy, and Continence Nurses, 32, 413-420. doi:10.1097/00152192-200511000-00014

Nausheen B, Gidron Y, Peveler R, \& Moss-Morris R (2009). Social support and cancer progression: A systematic review. Journal of Psychosomatic Research, 67, 403-415. doi:10.1016/j.jpsychores. 2008.12.012 [PubMed: 19837203]

NVivo 11 [software program]. (2015). Version 11. QSR International. Retrieved from http:// www.qsrinternational.com/nvivo-support/downloads

Patton MQ (2002). Qualitative research and evaluation methods (3rd ed.). Thousand Oaks, CA: Sage Publications.

Perdue DG, Haverkamp D, Perkins C, Daley CM, \& Provost E (2014). Geographic variation in colorectal cancer incidence and mortality, age of onset, and stage at diagnosis among American Indian and Alaska Native people, 1990-2009. American Journal of Public Health, 104, S404-414. doi:10.2105/AJPH.2013.301654 [PubMed: 24754657]

Plescia M, Henley SJ, Pate A, Underwood JM, \& Rhodes K (2014). Lung cancer deaths among American Indians and Alaska Natives, 1990-2009. American Journal of Public Health, 104, S388395. doi:10.2105/AJPH.2013.301609 [PubMed: 24754613]

Sandelowski M (1995). Sample size in qualitative research. Research in Nursing \& Health, 18(2), 179183. [PubMed: 7899572]

Sammarco A, \& Konecny LM (2008). Quality of life, social support, and uncertainty among latina breast cancer survivors. Oncology Nursing Forum, 35, 844-849. doi:10.1188/08.ONF.844-849 [PubMed: 18765332]

Sandelowski M (1996). Using qualitative methods in intervention studies. Research in Nursing \& Health, 19, 359-364. doi:10.1002/(SICI)1098-240X(199608)19:43.0.CO;2-H [PubMed: 8773558] 
Sandelowski M (2000). Whatever happened to qualitative description? Research in Nursing \& Health, 23, 334-340. doi:10.1002/1098-240X(200008)23:43.0.CO;2-G [PubMed: 10940958]

Sapp AL, Trentham-Dietz A, Newcomb PA, Hampton JM, Moinpour CM, \& Remington PL (2003). Social networks and quality of life among female long-term colorectal cancer survivors. Cancer, 98, 1749-1758. doi:10.1002/(ISSN)1097-0142 [PubMed: 14534893]

Singh SD, Ryerson AB, Wu M, \& Kaur JS (2014). Ovarian and uterine cancer incidence and mortality in American Indian and Alaska Native women, United States, 1999-2009. Journal Information, 104, 423-431.

Sullivan-Bolyai S, Bova C, \& Harper D (2005). Developing and refining interventions in persons with health disparities: The use of qualitative description. Nursing Outlook, 53, 127-133. doi:10.1016/ j.outlook.2005.03.005 [PubMed: 15988449]

U.S. Commission on Civil Rights. (2004). Native American health care disparities briefing: Executive summary. Washington, DC: Author.

White A, Richardson LC, Li C, Ekwueme DU, \& Kaur JS (2014). Breast cancer mortality among American Indian and Alaska Native women, 1990-2009. American Journal of Public Health, 104, S432-438. doi:10.2105/AJPH.2013.301720 [PubMed: 24754658]

Wilson SE, Andersen MR, \& Meischke H (2000). Meeting the needs of rural breast cancer survivors: What still needs to be done? Journal of Women's Health \& Gender-Based Medicine, 9, 667-677. doi: $10.1089 / 15246090050118198$

Wyatt G, \& Friedman LL (1996). Long-term female cancer survivors: Quality of life issues and clinical implications. Cancer Nursing, 19(1), 1-7. doi:10.1097/00002820-199602000-00001 [PubMed: 8904381]

Zucca AC, Boyes AW, Lecathelinais C, \& Girgis A (2010). Life is precious and I'm making the best of it: Coping strategies of long-term cancer survivors. Psycho-Oncology, 19, 1268-1276. doi: 10.1002/pon.v19:12 [PubMed: 20151408] 
Table 1.

Demographic characteristics of the sample $(\mathrm{N}=43)$.

\begin{tabular}{|c|c|c|c|}
\hline Variable & & N or Average & $\%$ \\
\hline Age, $M(S D)$ & Range: $32-77$ (years) & 56.33 & $(12.07)$ \\
\hline \multirow[t]{3}{*}{ Education, n (\%) } & Lower than high school diploma/GED & 1 & (2.3) \\
\hline & High school diploma/GED & 15 & $(34.9)$ \\
\hline & Greater than high school diploma/GED & 27 & $(62.8)$ \\
\hline \multirow[t]{4}{*}{ Marital status, $n(\%)$} & Married & 12 & $(27.9)$ \\
\hline & Divorced & 18 & $(41.9)$ \\
\hline & Separated, Widowed, Single & 11 & $(25.5)$ \\
\hline & Other & 2 & $(4.7)$ \\
\hline \multirow[t]{3}{*}{ Perceived health, $n(\%)$} & Poor or fair & 14 & $(32.5)$ \\
\hline & Good or excellent & 29 & $(67.5)$ \\
\hline & Less than $\$ 1,499$ & 21 & $(48.8)$ \\
\hline \multirow[t]{2}{*}{$\begin{array}{l}\text { Monthly household income, } \\
n(\%)\end{array}$} & $\$ 1,500-\$ 2,999$ & 14 & (32.6) \\
\hline & More than $\$ 3,000$ & 8 & (18.6) \\
\hline \multirow[t]{6}{*}{ Type of cancer, $n(\%)$} & Breast & 14 & $(32.6)$ \\
\hline & Cervical & 14 & (32.6) \\
\hline & Colon & 5 & (11.6) \\
\hline & Lung & 2 & $(4.7)$ \\
\hline & Non-Hodgkin Lymphoma & 2 & $(4.7)$ \\
\hline & Others & 6 & $(13.9)$ \\
\hline \multirow[t]{2}{*}{ Religion } & Yes & 39 & $(90.7)$ \\
\hline & No & 4 & (9.3) \\
\hline \multirow[t]{2}{*}{ Health insurance } & Yes & 40 & $(93.0)$ \\
\hline & No & 3 & (7.0) \\
\hline Time with cancer & Ranged from 3 month to 9 years & 2.42 & $(2.19)$ \\
\hline
\end{tabular}

J Evid Inf Soc Work. Author manuscript; available in PMC 2019 September 01. 